\title{
CARACTERIZAÇÃO MORFOLÓGICA, VIABILIDADE E VIGOR DE SEMENTES DE Tabebuia aurea (Silva Manso) Benth. \& Hook. f. ex. S. Moore ${ }^{1}$
}

\author{
Ademir Kleber Morbeck de Oliveira², Eloty Dias Schleder ${ }^{3}$ e Silvio Favero ${ }^{2}$
}

\begin{abstract}
RESUMO - A espécie Tabebuia aurea é encontrada em áreas de Cerrado, Caatinga, Floresta Amazônica e Pantanal, sendo utilizada para fins ornamentais, medicinais, construção civil, carpintaria e produção de carvão, entre outros. Por apresentar ampla utilização e distribuição, os objetivos deste estudo foram caracterizar morfologicamente e analisar a viabilidade e o vigor das sementes dessa espécie quando colhidas e armazenadas por diferentes períodos. As sementes foram germinadas recém-colhidas, 30, 60 e 90 dias após o armazenamento em laboratório e em campo, sendo também submetidas ao teste de tetrazólio. As sementes mediram, em média, 57,8 x 20,6 x 3,1 mm (com alas) e 17,3 x 13,3 x 1,7 mm (sem alas), sendo assimétricas. Seu peso médio foi de 13,18 $\mathrm{g}$ (com alas) e 11,55 g (sem alas). As sementes apresentaram maior viabilidade quando recém-colhidas, maior porcentagem de germinação em laboratório após 30 dias de armazenamento e maior porcentagem de germinação acumulada a campo quando semeadas na superfície. A viabilidade das sementes, medida através do teste de tetrazólio, apresentou resultados similares aos obtidos por meio do teste de germinação em laboratório, indicando ser esse teste adequado para medir a viabilidade desta espécie.
\end{abstract}

Palavras-chave: Sementes florestais, produção de mudas, banco de sementes, germinação e Tabebuia aurea.

\section{MORPHOLOGICAL CHARACTERIZATION, VIABILITY AND VIGOR OF Tabebuia aurea (Silva Manso) Benth. \& Hook. f. ex. S. Moore SEEDS}

\begin{abstract}
Tabebuia aurea is found in areas of Cerrado, Caatinga, Amazon Forest and Pantanal., It is used medicinally, for landscaping, and as timber for construction. For presenting wide use and distribution, the objective of this study was to characterize morfologically and analyze the viability and vigor of the harvested seeds of this species originated from the Cerrado. The seeds were germinated immediately after harvest and at 30, 60 and 90 days after the storage in laboratory and field, being also tested with tetrazolium. Seeds measured, in average, $57.8 \times 20.6 \times 3.1 \mathrm{~mm}$ (with wings) and $17.3 \times 13.3 \times 1.7 \mathrm{~mm}$ (without wings), which were antisymmetrical. The average seed weight was $13.18 \mathrm{~g}$ (with wings) and $11.55 \mathrm{~g}$ (without wings). $\boldsymbol{T}$. Aurea presented greater viability immediately after harvest, greater percentage of germination in laboratory 30 days after storage, and greater percentage of accumulated germination on field surface. Seed viability, checked by the tetrazolium test, gave results similar to the ones obtained from the germination test in laboratory, indicating that it is satisfactory to test the viability of this species.
\end{abstract}

Keywords: Forest seeds, seedling production, seed bank, germination and Tabebuia aurea.

\footnotetext{
${ }^{1}$ Recebido em $1^{\circ}$.06.2004 e aceito para publicação em 10.11.2005.

${ }^{2}$ Programa de Pós-Graduação em Meio Ambiente e Desenvolvimento Regional da UNIDERP, Cx. Postal 2153, 79031-320 Campo Grande-MS. E-mail: <ademiroliveira@mail.uniderp.br>; <silviofavero@mail.uniderp.br>.

${ }^{3}$ Programa de Pós Graduação em Meio Ambiente e Desenvolvimento Regional da UNIDERP. E-mail: <schdias@terra.com.br> .
} 


\section{INTRODUÇÃO}

O conhecimento das características morfológicas e ecofisiológicas das sementes, visando a uma posterior produção de mudas para recuperar e, ou, enriquecer áreas degradadas, resultantes da exploração desordenada dos recursos naturais, é importante para a manutenção da biodiversidade. A falta de informações básicas sobre as espécies nativas dificulta o aproveitamento destas nos programas silviculturais, sendo fundamentais os estudos germinativos (FERREIRA, 2000); para esse fim, o conhecimento da anatomia, morfologia e fisiologia das sementes é de grande importância, pois o plantio dessas espécies exige cuidados especiais (ATHIÉ et al., 1998).

A semente é o principal meio para a reprodução da maioria das espécies lenhosas, e suas características morfológicas externas, por não variarem com as condições ambientais, são importantes para auxiliar a identificação da família, gênero e espécie, além de o seu conhecimento poder auxiliar os estudos de germinação e armazenamento e os métodos de cultivo (GROTH, 1985; AMORIM et al., 1997).

Como a produção de sementes é limitada no tempo, o estudo do comportamento das sementes durante o armazenamento destas para posterior produção de mudas é de fundamental importância, pois, quando conservadas por determinados períodos e condições, podem perder sua capacidade germinativa.

Para verificar a qualidade das sementes é necessário aplicar o teste de germinação, realizado em laboratório, que determina em uma amostra a proporção de sementes vivas e capazes de produzir plantas normais sob condições favoráveis. Entretanto, quando se trata da utilização para semeadura em campo, onde freqüentemente as condições não são favoráveis, os resultados podem ser inferiores, causando, assim, erros nas estimativas esperadas. Esse tipo de teste tem maior validade para espécies de interesse econômico. Quando se trabalha com espécies nativas, os resultados são mais complexos para serem interpretados (BRASIL, 1992; EIRA e NETTO, 1998; CARVALHO e NAKAGAWA, 2000).

Outra característica importante da semente é a viabilidade, que é a habilidade de germinar por períodos variáveis e geneticamente determinados. Os fatores ambientais e as condições de armazenamento têm efeitos decisivos na viabilidade de qualquer espécie (MALAVASI, 1988). Os testes de viabilidade podem ser diretos e indiretos, em que os diretos determinam a germinação, medindo a emergência e avaliação de plântulas, enquanto os indiretos estimam a capacidade germinativa da semente. O teste de tetrazólio, um teste indireto, é o que vem apresentando os melhores resultados, pois permite uma rápida estimativa da germinação e também o diagnóstico da situação da semente(PIÑA-RODRIGUES e SANTOS, 1988; FRANÇA NETO, 1999; CARVALHO e NAKAGAWA, 2000).

O vigor, um teste direto, detecta as modificações deletérias mais sutis, resultante do avanço da deterioração, não revelados pelo teste de germinação, refletindo um conjunto de características que determinam o potencial para a emergência rápida e uniforme de plântulas normais, sob ampla diversidade de condições ambientais, pois não basta que as sementes tenham altos índices de germinação, sendo também necessário que estas, mesmo em condições desfavoráveis de campo, germinem e se estabeleçam (MARCOS FILHO, 1999).

O tamanho das sementes também exerce influência no processo de germinação. Exemplo disso é que as sementes menores germinam primeiro, pois necessitam de menor quantidade de água para fazê-lo. No entanto, como possuem tecidos de reserva mais volumosos e produzem plântulas mais pesadas, as sementes maiores tendem a emergir mais rapidamente (NAKAGAWA, 1992; CARVALHO e NAKAGAWA, 2000).

A espécie Tabebuia aurea (ipê-amarelo, paratudo) é uma espécie de ampla distribuição no território brasileiro, ocorrendo nas regiões Amazônica, no Cerrado, na Caatinga e no Pantanal Mato-Grossense, onde forma os Paratudais (LORENZI, 1992; POTT e POTT, 1994). Sua presença é indício de terra boa para pasto (ALMEIDA et al., 1998). É também utilizada para fins ornamentais, sendo considerada melífera (BRANDÃO e FERREIRA, 1991). Sua madeira é dura, consumida na construção civil, carpintaria e fabricação de carvão (van der BERG, 1986; CONCEIÇÃO e PAULA, 1986). O chá da casca e entrecasca é utilizado como diurético, e as raízes curtidas na cachaça ou vinho são empregadas no tratamento da gripe (BARRETO, 1990). As características ecológicas de várias espécies do gênero Tabebuia tornam seu estudo importante devido à sua importância silvicultural e utilização social, além de seu uso medicinal (LORENZI, 1992; POTT e POTT, 1994).

Levando-se em consideração a necessidade do melhor conhecimento das espécies nativas, Tabebuia 
aurea (Manso) Benth. \& Hook. f. ex S. Moore, coletada em área de Cerrado, foi selecionada para este trabalho, tendo como objetivo o estudo das características relacionadas a morfologia, germinação, viabilidade, vigor e tempo de armazenamento das sementes, fundamental para a produção de mudas.

\section{MATERIAL E MÉTODOS}

O trabalho foi realizado no Campus de Ciências Biológicas, Agrárias e da Saúde (CCBAS), no Laboratório de Morfologia Vegetal da Universidade para o Desenvolvimento do Estado e da Região do Pantanal (UNIDERP), Campo Grande, MS.

Durante o mês de setembro de 1999, os frutos de T. aurea foram coletados de árvores adultas, com o auxílio de tesoura de poda alta, em praças, parques e cerrados na região de Campo Grande, MS, 20 26' 34 " sul e 54 38 ' 47" oeste. Levando-se em conta o porte, o vigor e a sanidade, as árvores-matriz foram escolhidas e posteriormente identificadas com plaquetas de plástico. Após colhidos, os frutos foram deixados à sombra por uma semana para secar até a deiscência natural, expondo as sementes que foram coletadas manualmente. Estas foram acondicionadas em sacos de papel Kraft e armazenadas em temperatura ambiente $\left( \pm 24^{\circ} \mathrm{C}\right.$ ), sendo os testes realizados com sementes recém-colhidas (sem armazenamento) e após 30, 60 e 90 dias de armazenamento (DA).

Caracterização morfológica das sementes - Foram retirados e separados dois lotes de 50 sementes cada. O primeiro lote foi utilizado para analisar a cor, forma e superfície externa, bem como as estruturas que compõem as sementes. Já as descrições morfológicas das sementes foram feitas através de observações realizadas em estereomicroscópio. Após as medidas, as sementes foram descartadas. Através do segundo lote, foram medidos o comprimento, a largura e a espessura (com e sem alas), utilizando-se paquímetro digital e o peso da matéria seca, após secagem em estufa a $65^{\circ} \mathrm{C}$, por $48 \mathrm{~h}$, através de balança analítica de precisão.

Germinação em laboratório - O teste foi realizado com sementes recém-colhidas e aos 30, 60 e 90 dias de armazenamento, sendo colocados para germinar, a cada período, três lotes de 50 sementes com alas em Germinador Prolab, tipo Mangelsdorf, à temperatura de $28^{\circ} \mathrm{C}$, em três caixas Gerbox, forradas internamente com uma folha de papel-filtro umedecido com água.
A leitura dos testes foi realizada a cada 48 horas, durante 10 dias, sendo consideradas germinadas as sementes que apresentaram raiz primária superior a $2 \mathrm{~mm}$.

Teste de viabilidade - Lotes de 100 sementes sem alas foram acondicionados entre duas folhas de papel-filtro, embebidas em reagente de tetrazólio 0,1\% e mantidas no escuro durante $24 \mathrm{~h}$, à temperatura de $28^{\circ} \mathrm{C}$ (MARCOS FILHO, 1999; PIÑA-RODRIGUES e SANTOS, 1988).

As leituras dos resultados foram realizadas $24 \mathrm{~h}$ após o teste, seccionando-se longitudinalmente as sementes com uma lâmina de barbear. Consideraramse viáveis as sementes que apresentaram de 76 a 100\% (classe 4) de suas áreas vitais, eixo embrionário e cotilédones, corados de vermelho-carmim-claro, além de turgor dos tecidos e estruturas do embrião desenvolvidas e intactas, segundo método utilizado por Lee (1972). Foram consideradas de média viabilidade as sementes com índice entre 51 e $75 \%$ de suas áreas vitais coradas (classe 3 ); baixa viabilidade com índice entre 26 e 50\% de suas áreas vitais coradas (classe 2); e muito baixa viabilidade, com índice entre 0 e $25 \%$ de suas áreas vitais coradas (classe 1 ).

Vigor em campo - Os testes de vigor foram realizados em campo, com fornecimento de água pela manhã e à tarde, através de irrigação, em solo arenoargiloso, sem adição de adubos químicos ou orgânicos. A semeadura foi efetuada em três canteiros com $4 \mathrm{~m}$ x 0,90 m, sorteados ao acaso em relação à época e profundidade, em delineamento experimental inteiramente casualizado.

Para os testes foram empregadas 150 sementes, em três repetições de 50 sementes. Cada repetição foi semeada em solo, previamente revolvido e nivelado, em diferentes estratos de profundidade (semeadura na superfície; 2,5; 5; e $10 \mathrm{~cm}$ ), com espaçamento de $3 \mathrm{~cm}$ entre sementes e $10 \mathrm{~cm}$ entre linhas. Após a semeadura foi realizada a irrigação, bem como o controle físico de insetos (VIEIRA e CARVALHO, 1994).

O vigor relativo das sementes foi avaliado através da porcentagem de emergência de plântulas em campo (BRASIL, 1992), efetuando-se contagens do número de plântulas emersas a cada 48 horas, durante 30 dias após a semeadura, sendo os dados tabulados e transformados para log $(\mathrm{x}+1)$ e submetidos à Análise 
de Regressão Múltipla, que permite melhor visualização dos dados, ajustados a um modelo matemático para estimar os efeitos da profundidade de semeadura e do tempo de armazenamento (variáveis independentes) sobre a emergência das plântulas.

\section{RESULTADOS E DISCUSSÃO}

Caracterização morfológica - As sementes apresentam expansões aladas bilaterais, tendo a testa expansões aliformes alvas, assimétricas, fibrosas e aveludadas ao tato. Mediram, em média, com alas, 57,8 x 20,6 x 3,1 mm e sem alas, 17,3 x 13,3 x 1,7 mm, com diferenças significativas quando mensuradas com e sem alas. A espécie apresentou uma assimetria entre suas alas, fator que pode interferir na dispersão, favorecendo-a, pois pode propiciar maior distância percorrida quando levada pelo vento. Klaus (2001), estudando a morfologia de T. aurea, obteve a média de 60,0 mm de comprimento e 15,4 mm de largura, com alas e 10,0 mm de comprimento e 4,6 $\mathrm{mm}$ de largura, sem alas, verificando-se o maior tamanho das sementes de T. aurea deste trabalho e indicando variações de tamanho, na dependência do local de coleta. O peso médio de 50 sementes foi de 13,18 g com alas e 11,55 g sem alas (Tabela 1), podendo ser consideradas pesadas quando comparadas com sementes de outras espécies de ipê, como T. impetiginosa - 1,25 g (com alas) e 0,88 g (sem alas) (SCHLEDER et al., 2003), e, dessa maneira, facilitando seu estabelecimento no ambiente, pois as sementes que possuem maior reserva nutritiva podem fixar-se mais facilmente (CARVALHO e NAKAGAWA, 2000).

Na região do núcleo seminífero, observou-se, dorsalmente, o funículo constituindo uma estrutura protetora para a radícula do embrião e ventralmente o hilo, representado por uma porção côncava em depressão, de coloração escura, com bordas salientes. Não se observou nitidamente a rafe. Essa região é ricamente fibrosa, porém macia ao tato. O embrião apresentou-se mais largo do que longo, de consistência carnosa; bilobado no ápice e na base. Os cotilédones apresentaram-se levemente assimétricos, e a semente exibiu eixo radícula-hipocótilo bem constituído. Schleder et al. (2003), trabalhando com T. impetiginosa, encontraram características morfológicas semelhantes, indicando que nesse grupo e nesse parâmetro não existem diferenças marcantes.

R. Árvore, Viçosa-MG, v.30, n.1, p.25-32, 2006
Tabela 1 - Caracterização e peso médio de 50 sementes (g) de Tabebuia aurea, com e sem alas

Table 1 - Characterization and mean weight of $50(\mathrm{~g})$ Tabebuia aurea seeds, with and without wings

\begin{tabular}{lcccc}
\hline $\begin{array}{l}\text { Tabebuia } \\
\text { aurea }\end{array}$ & $\begin{array}{c}\text { Comprimento } \\
(\mathrm{mm})\end{array}$ & $\begin{array}{c}\text { Largura } \\
(\mathrm{mm})\end{array}$ & $\begin{array}{c}\text { Espessura } \\
(\mathrm{mm})\end{array}$ & $\begin{array}{c}\text { Peso } \\
(\mathrm{g})\end{array}$ \\
\hline Com alas & $57,8 \pm 10,5$ & $20,6 \pm 2,5$ & $3,1 \pm 1,1$ & 13,18 \\
Sem alas & $17,3 \pm 1,4$ & $13,3 \pm 1,1$ & $1,7 \pm 0,4$ & 11,55 \\
\hline
\end{tabular}

1/Média \pm desvio-padrão.

Germinação em laboratório - Na Figura 1 é apresentada a porcentagem de germinação acumulada das sementes de T. aurea recém-colhidas e aos 30, 60 e 90 DA.

Nessa espécie, com sementes recém-colhidas, obteve-se, em média, uma germinação acumulada de 86\%; aos 30 DA 90\%, aos 60 DA 58\% e aos 90 DA $78 \%$, sendo a média geral em torno de $78 \%$.

Pode-se observar que as maiores taxas de germinação acumulada ocorreram nas sementes recém-colhidas e aos 30 DA. Após esse período, as taxas oscilam, diminuindo aos 60 DA e aumentando aos 90 DA, porém indicando perda gradativa de viabilidade. Essa variabilidade pode indicar uma estratégia adaptativa, em que a espécie procura distribuir seu período germinativo para aproveitar condições ambientais favoráveis, que ocorrem em diferentes épocas após sua frutificação e liberação de sementes.

Maeda e Mathes (1984), investigando a viabilidade das sementes de Tabebuia chrysotricha, T. avellanedae, T. impetiginosa, T. rosea e T. heptaphylla, encontraram diferentes índices de germinação e viabilidade nesse gênero, quando armazenadas em vidros herméticos ou em sacos de papel, ressaltando-se que as sementes guardadas em vidros, à temperatura de $30{ }^{\circ} \mathrm{C}$, apresentaram menor longevidade. Resultados similares foram citados por Pott e Pott (1994). Cabral et al. (2003) obtiveram índices de germinação altos (acima de 80\%) até os 120 dias, provavelmente devido ao fato de as sementes serem armazenadas em câmara fria e seca.

Teste de viabilidade - Na Figura 2 são apresentados os resultados do teste de tetrazólio, realizado em quatro épocas de armazenamento.

Considerando-se as classes 3 e 4, para sementes recém-colhidas a espécie apresentou 94\% de viabilidade; aos 30 DA 82\%, aos 60 DA $60 \%$ e aos 90 DA 66\%, indicando que essa espécie exibe maior viabilidade quando recém-colhida. 


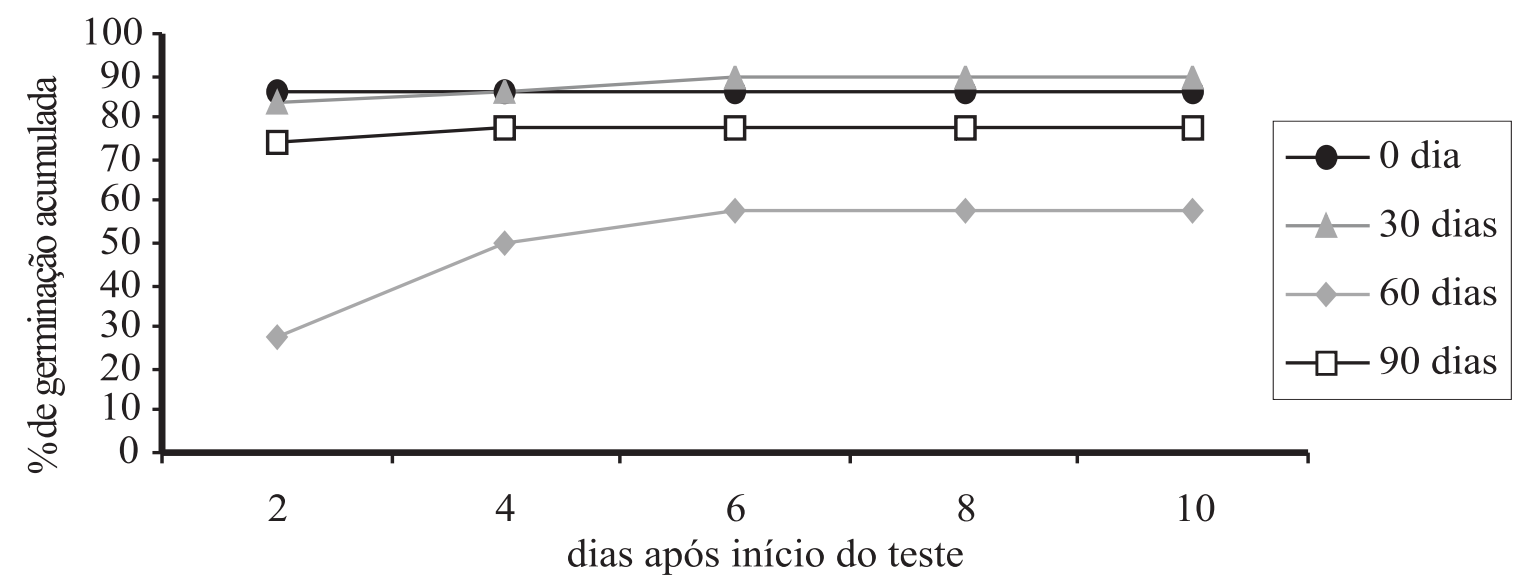

Figura 1 - Porcentagem de germinação de sementes de Tabebuia aurea, a $28^{\circ} \mathrm{C}$, recém-colhidas e após 30 , 60 e 90 dias de armazenamento.

Figure 1 - Percentage of germination of Tabebuia aurea seeds, at $28^{\circ} \mathrm{C}$, immediately after harvest and at 30,60 and 90 days of storage.

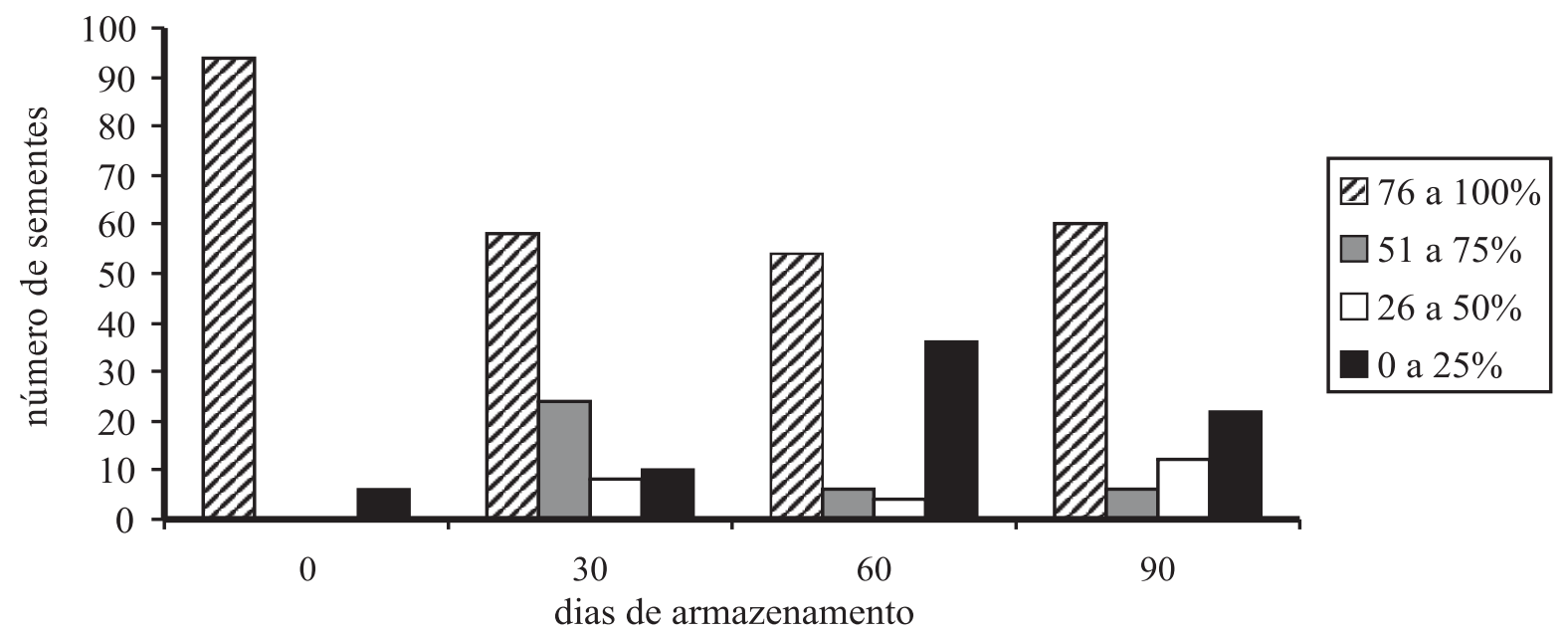

Figura 2 - Categorias de viabilidade (teste de tetrazólio) em sementes de Tabebuia aurea em quatro épocas de armazenamento (0, 30, 60 e 90 DA).

Figure 2 - Tetrazolium test of Tabebuia aurea seeds, distribute in four classes of seed viability and four storage periods $(0,30,60$ and $90 \mathrm{DA})$.

Sementes de T. aurea estocadas em embalagens de papel ou mantidas em recipientes de vime, abertos e em condições ambientais que possibilitam as trocas gasosas com o meio possuem viabilidade não superior a 60 dias (SOUSA, 1993), resultado esse diferente dos encontrados neste trabalho, em que a viabilidade ultrapassou 90 dias. A diferença de resultados provavelmente está ligada à origem das sementes (Mato Grosso do Sul-São Paulo). Também Maeda e Mathes
(1984) colocaram que as sementes de Tabebuia apresentam maior tempo de viabilidade quando são mantidas à temperatura ambiente e acondicionadas em embalagens do tipo não-hermético. Já Cunha et al. (1992), trabalhando com três espécies de Tabebuia, verificaram que o armazenamento no longo prazo dessas sementes pode ser efetuado em banco de germoplasma a $-20{ }^{\circ} \mathrm{C}$, desde que sua umidade seja inferior a $10 \%$. 
O teste de tetrazólio, utilizando-se as classes 3 e 4, apresentou resultados similares aos encontrados na germinação em laboratório, com diferenças de viabilidade e germinação entre 2 e $12 \%$, indicando que o teste é adequado para analisar a viabilidade de sementes de T. aurea. A degradação dos tecidos, visualizada no teste, não impede a germinação, apesar da diminuição gradativa desta.

Vigor - Na Tabela 2, apresenta-se uma estimativa da germinação em campo (vigor), com sementes colocadas para germinar na superfície e nas profundidades de 2,5; 5; e $10 \mathrm{~cm}$, em quatro épocas diferentes. Podese observar, nessa tabela, que a maior taxa de emergência ocorreu no lote de sementes recém-colhidas semeadas na superfície. E, quanto maiores a profundidade e o tempo de armazenamento, menores as taxas de emergência.

Da superfície para $2,5 \mathrm{~cm}$ de profundidade de semeadura, com sementes recém-colhidas, houve redução de $86 \%$; $94 \%$ para $5 \mathrm{~cm}$ e $97 \%$ para $10 \mathrm{~cm}$. Essa redução pode estar associada à menor disponibilidade de oxigênio nas maiores profundidades do solo ou à barreira natural imposta pelo próprio substrato. Quanto ao tempo de armazenamento, houve redução de $27 \%$ na emergência de plântulas provenientes de sementes recém-colhidas quando comparadas com 30 DA, 32\% para 60 DA e 35\% para 90 DA, indicando que, nas condições de campo, existe maior germinação de sementes recém-colhidas, (65\%), com uma estabilização das taxas de germinação na faixa de 42 a $47 \%$, nas épocas de armazenagem de 90, 60 e 30 dias. As sementes, viáveis em laboratório, não conseguem germinação total em campo, o que provavelmente está ligado aos fatores ambientais que selecionam as sementes mais vigorosas.

Tabela 2 - Estimativa da germinação em campo de sementes de Tabebuia aurea recém-colhidas e após 30, 60 e 90 dias de armazenamento, semeadas na superfície e a 2,5 ; 5 ; e $10 \mathrm{~cm}$ de profundidade

Table 2 - Estimate of germination in the field of Tabebuia aurea sown on the surface, 2,5, 5 and $10 \mathrm{~cm}$ depth, immediately after harvest and at 30,60 and 90 days of storage

\begin{tabular}{lcccc}
\hline Dias após o & \multicolumn{4}{c}{ Profundidade $(\mathrm{cm})$} \\
\cline { 2 - 5 } Armazenamento & 0 (superfície) & 2,5 & 5 & 10 \\
\hline 0 (recém-colhida) & 65 & 9,0 & 3,9 & 1,5 \\
30 & 47 & 6,5 & 2,8 & 1,1 \\
60 & 44 & 6,1 & 2,6 & 1,0 \\
90 & 42 & 5,9 & 2,5 & 1,0 \\
\hline
\end{tabular}

$\log ($ germinação +1$)=1,81-0,0934 \log ($ tempo +1$)-1,57 \log$ (profundidade +1$)\left(r^{2}=81,5 \%\right)$.
Essa maior emergência de plântulas para a semeadura superficial pode caracterizar a formação de um banco de plântulas e também um banco de sementes na serrapilheira. Conseqüentemente, solos desprotegidos e sujeitos à erosão provavelmente dificultariam o estabelecimento dessa espécie.

O gênero Tabebuia apresenta tendência de floração seqüencial, apresentando, por determinado período, exemplares floridos e com a presença de frutos maduros. Tal fator possibilita distribuir as épocas de germinação em função da sazonalidade, aproveitando melhor as variações climáticas e distribuindo suas plântulas por um período maior de tempo, o que possibilita maiores taxas de estabelecimento. Essa maior amplitude permite melhor adaptação ao meio, pois as plântulas possuem maior probabilidade de encontrar condições satisfatórias para seu estabelecimento. Em espécies florestais, tendose em vista a irregularidade de produção de sementes, a perda de uma florada pode ser bastante negativa (VILAGOMEZ et al. apud EIRA e NETTO, 1998).

\section{CONCLUSÃO}

As sementes de T. aurea apresentam maior viabilidade quando recém-colhidas, maior porcentagem de germinação em laboratório aos 0 e 30 DA e maior porcentagem de germinação acumulada em campo, quando semeadas na superfície e recém-colhidas, com a ressalva de que a estimativa de germinação em campo que propicia melhor resultado ocorre quando a semente é semeada na superfície, em qualquer época de armazenamento. O teste de tetrazólio é adequado para medir a viabilidade das sementes dessa espécie.

\section{REFERÊNCIAS BIBLIOGRÁFICAS}

ALMEIDA, S. P. et al. Cerrado: espécies vegetais úteis. Planaltina: EMBRAPA - CPAC, 1998. 464p.

AMORIM, I. L.; DADIVE, A. C.; CHAVES, M. M. F. Morfologia do fruto e da semente, e germinação da semente de Trema micrantha (L.) Blum.

Cerne, v. 3, n. 1, p. 138-152, 1997.

ATHIÉ, I. et al. Conservação de grãos. Campinas: Fundação Cargill, 1998. 236 p.

BARRETO, L. V. F. Trilha ecológica - Guia de campo. Brasília: Coronário, 1990. 19p. 
van der BERG, M. E. Formas atuais e potenciais de aproveitamento das espécies nativas e exóticas do Pantanal Mato-Grossense. In: SIMPÓSIO SOBRE RECURSOS NATURAIS E SÓCIOECONÔMICO DO PANTANAL, 1., 1986, Corumbá. Anais... Corumbá: 1986. p. 131-136.

BRANDÃO, M.; FERREIRA, P. B. D. Flora apícola do cerrado. Informe Agropecuário, v. 15, n.168, p. 7-14, 1991.

BRASIL. Ministério da Agricultura e Reforma Agrária. Regras para Análise de Sementes. Brasília: DNDV/CLAV, 1992. 365p.

CABRAL, E. L.; BARBOSA, D. C. A.; SIMABUKURO, E. A. Armazenamento e germinação de sementes de Tabebuia aurea (Manso) Benth. \& HooK. F. Ex. S. Moore. Acta Botanica Brasilica, v. 17, n. 4, p. 609-617, 2003.

CARVALHO, N. M.; NAKAGAWA, J. Sementes: ciência, tecnologia e produção. Jaboticabal: FUNEP, 2000. 588p.

CONCEIÇÃO, C. A.; PAULA, J. E. Contribuição para o conhecimento da flora do Pantanal Mato Grossense e sua relação com a fauna e o homem. In: SIMPÓSIO SOBRE RECURSOS NATURAIS E SÓCIO-ECONÔMICOS DO PANTANAL, 1., 1986, Corumbá. Anais... Corumbá: 1986. p.107-130.

CUNHA, R. et al. Métodos para conservação a longo prazo de sementes de Tabebuia spp. Bignoniaceae. In: CONGRESSO NACIONAL SOBRE ESSÊNCIAS NATIVAS, 2., 1992, São Paulo. Anais... São Paulo: Instituto Florestal, 1992. v.4, p.675-678.

EIRA, M. T. S.; NETTO, D. A. M. Germinação e conservação de sementes de espécies lenhosas. In. RIBEIRO, J. F. Cerrado: matas de galeria. Planaltina: EMBRAPA - CPAC, 1998. p. 97-117.

FERREIRA, C. A. C. Recuperação de áreas degradadas. Informe Agropecuário, v. 21, n. 202, p. 127-130, 2000.
FRANÇA NETO, J. B. Teste de tetrazólio para determinação do vigor de sementes. In: KRZYZANOWSKI, F. C.; VIEIRA, R. D.; FRANÇA NETO, J. B. Vigor de sementes: conceitos e testes. Londrina: ABRATES, 1999. 218p.

GROTH, D. Caracterização morfológica das unidades de dispersão e das plântulas de espécies invasoras das tribos Anthemidae, Astereae e cichorieae (Compositae). Revista Brasileira de Botânica, v. 7, n. 3, p. 49-94, 1985.

KLAUS, P. R. Morfologia da semente de nove espécies arbóreas do gênero Tabebuia (Bignoniaceae), do Estado Mato Grosso do Sul, Brasil. 2001. $48 \mathrm{f}$. Monografia (Graduação em Ciências Biológicas) Universidade para o Desenvolvimento do Estado e da Região do Pantanal, Campo Grande, 2001.

LEE, A. E. Crescimento e desenvolvimento das plantas. 2. ed. São Paulo: EDART, 1972. 96p.

LORENZI, H. Árvores brasileiras: manual de identificação e cultivo de plantas arbóreas nativas do Brasil. Nova Odessa: Plantarum, 1992. 352p.

MAEDA, J. A.; MATHES, L. A. F. Conservação de Sementes de Ipê. Bragantia, v. 43, n. 1, p.51-61, 1984.

MALAVASI, M. M. Germinação de sementes. In: PIÑA-RODRIGUES, F. C. M. (Coord.) Manual de análises de sementes florestais. Campinas: Fundação Cargil, 1988. p. 44-67.

MARCOS FILHO, J. Testes de vigor: importância e utilização - In: KRZYZANOWSKI, F. C.; VIEIRA, R. D.; FRANÇA NETO, J. B. Vigor de sementes: conceitos e testes. Londrina: ABRATES, 1999. 218 p.

NAKAGAWA, J. Teste de vigor baseado na avaliação de plântulas. In: Curso sobre teste de vigor em sementes, 14-17/09/1992. FCAV/ UNESP. Jaboticabal: FUNEP, 1992. p.76-95.

POTT. A.; POTT, V. J. Plantas do Pantanal. Corumbá: EMBRAPA/CPAP - SPI, 1994. 320p.

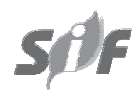

R. Árvore, Viçosa-MG, v.30, n.1, p.25-32, 2006 
PIÑA-RODRIGUES, F. C. M.; SANTOS, N. R. F. Teste de Tetrazólio. In: RODRIGUES, F. C. M. P. (Coord.).

Manual de análise de sementes florestais. Campinas: Fundação Cargil, 1988. p. 32-44.

SCHLEDER, E. J. D.; OLIVEIRA, A. K. M.;

FAVERO, S. Caracterização morfológica,

viabilidade e vigor de sementes de Tabebuia impetiginosa (Mart.) Standl - BIGNONIACEAE. Ensaios e Ciências - Série Agrárias, v.7, p. 271-282, 2003.
SOUSA, A. V. G. Morfologia,

desenvolvimento e anatomia de

Tabebuia caraiba (Mart.) Bur.

Bignoniaceae. 1993. 379f. Tese (Doutorado em Morfologia Vegetal) - Universidade de São Paulo, São Paulo, 1993.

VIEIRA, R. D.; CARVALHO, N. M. Testes de vigor em sementes. Jaboticabal: FUNEP, 1994. 164p. 